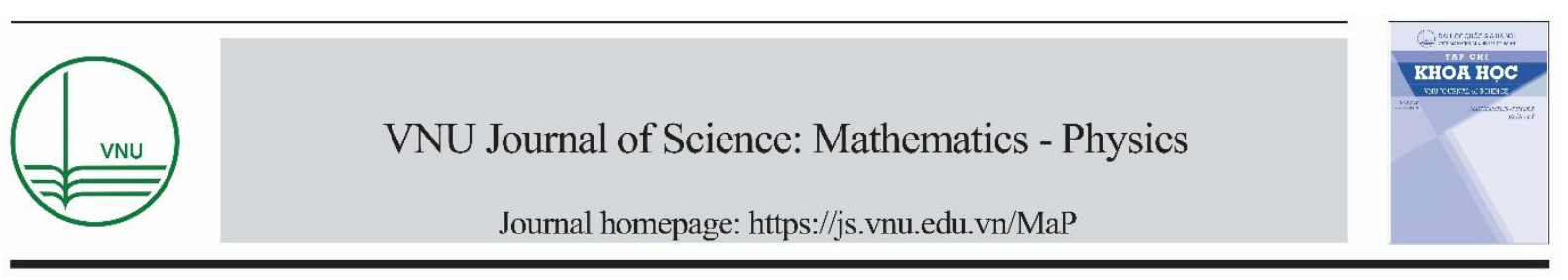

Original Article

\title{
Characteristics of Ag-Doped ZnO Thin Films Prepared by Sputtering Method
}

\author{
Tran Thi Ngoc Anh ${ }^{1}$, Tran Thi Ha ${ }^{1,2}$, \\ Nguyen Viet Tuyen ${ }^{1, *}$, Pham Nguyen Hai ${ }^{1}$ \\ ${ }^{1}$ Faculty of Physics, VNU University of Science, \\ 334 Nguyen Trai, Thanh Xuan, Hanoi, Vietnam \\ ${ }^{2}$ Faculty of Basic Science, Hanoi University of Mining and Geology, Duc Thang, \\ North Tu Liem, Hanoi, Vietnam \\ Received 05 August 2019 \\ Revised 25 September 2019; Accepted 09 October 2019
}

\begin{abstract}
This paper presents the preparation of Ag-doped $\mathrm{ZnO}$ bulk sample by solid state reaction and Ag-doped $\mathrm{ZnO}$ thin films by sputtering method. The effects of doping concentration $(1,2$ and $4 \%)$ on the properties of the thin films were investigated. Various methods were utilized to investigate characteristics of the samples: X-ray diffraction, Raman scattering spectroscopy, photoluminescence, energy dispersive X-Ray spectroscopy, scanning electron microscopy, atomic force microscope, absorption spectroscopy and Hall measurement. The study results show that $\mathrm{Ag}$ diffused into $\mathrm{ZnO}$ crystal lattice after heat treatment at $1,200^{\circ} \mathrm{C}$. As-prepared thin film samples exhibited low resistivity in the order of $10^{-3} \Omega . \mathrm{cm}$. The film doped with $2 \% \mathrm{Ag}$ shows the lowest resistivity of $1.8 \times 10^{-3} \Omega . \mathrm{cm}$, which is potential for making transparent electrodes in optoelectronics.
\end{abstract}

Keywords: Transparent conductive oxide, $\mathrm{ZnO}$ :Ag, sputtering, Hall measurement.

\section{Introduction}

For decades, transparent conductive oxide (TCO) has been studied and widely used in electronic devices. For processing the electrodes, TCO needs to have low resistivity $\left(\rho \sim 10^{-3} \Omega . \mathrm{cm}\right)$ and high transmittance (>70\%). Many studies reported fabrication of doped $\mathrm{ZnO}$ thin film with low resistivity

\footnotetext{
${ }^{*}$ Corresponding author.

Email address: nguyenviettuyen@ hus.edu.vn
}

https//doi.org/ 10.25073/2588-1124/vnumap.4365 
in the order of $10^{-4} \div 10^{-2} \Omega . \mathrm{cm}$. Among commonly used dopants for $\mathrm{ZnO}$, the most promising candidates are $\mathrm{Al}, \mathrm{In}, \mathrm{Ga}, \mathrm{Co}, \mathrm{P} . . .[1-5]$. Ag is also considered as suitable for doping into $\mathrm{ZnO}$ thanks to properties such as antibacterial ability, high conductivity, low absorption coefficient in visible region [6-8]. However, the number of studies on $\mathrm{Ag}$ doped $\mathrm{ZnO}$ is less than those on others metal dopants.

$\mathrm{Ag}$ doped $\mathrm{ZnO}$ ( $\mathrm{ZnO}: \mathrm{Ag}$ ) shows both $\mathrm{n}$ and $\mathrm{p}$ type conduction, depending on $\mathrm{Ag}$ location in $\mathrm{ZnO}$ crystal lattice [9]. A substitution of $\mathrm{Ag}^{+}$at $\mathrm{Zn}^{2+}$ site will create shallow acceptor, making $\mathrm{ZnO}$ a p-type semiconductor. On the other hand, if Ag locates at interstitial sites or O sites, donor levels will be formed in bandgap, then $\mathrm{ZnO}$ will become $\mathrm{n}$-type semiconductor. Since these defects altogether coexist in $\mathrm{ZnO}$ lattice, the conduction type of $\mathrm{ZnO}$ depends on the competition between $\mathrm{Ag}+\mathrm{Zn}$ and $\mathrm{Ag}_{\mathrm{i}}$.

Some techniques have been used to fabricate Ag-doped $\mathrm{ZnO}$ thin film such as pulsed laser deposition (PLD), molecular beam epitaxy (MBE), radio frequency sputtering. Using PLD method, Guptan [10] prepared n-type $\mathrm{ZnO}: \mathrm{Ag}$ thin film with resistivity of $3 \times 10^{-3} \Omega \mathrm{cm}$. Myers [9] produced 2 types of $\mathrm{ZnO}: \mathrm{Ag}$ thin film: n-type with resistivity of $2 \Omega . \mathrm{cm}$ and p-type with resistivity of $200 \Omega . \mathrm{cm}$. Kim [11] reported the success of fabricating p-type $\mathrm{ZnO}: \mathrm{Ag}$ thin film with resistivity of $7.25 \times 10^{-2}$ $\Omega . c m$ by MBE technique. N-type and p-type ZnO thin films were also deposited by Deng [12] in 2010 by sputtering with resistivity of $0.85 \Omega . \mathrm{cm}$ and $18.2 \Omega . \mathrm{cm}$, respectively. The resistivity of Ag-doped $\mathrm{ZnO}$ in literature is still relatively high for making electrodes.

In this paper, we present the results of manufacturing and studying properties of $\mathrm{Ag}$ doped $\mathrm{ZnO}$ bulk samples by solid state reaction and $\mathrm{ZnO}: \mathrm{Ag}$ thin films by sputtering method. The fabricated $\mathrm{ZnO}: \mathrm{Ag}$ thin films have low resistivity in the order of $10^{-3} \Omega \mathrm{cm}$, which are potential candidates for transparent electrodes in optoelectronics.

\section{Experiment}

All materials were purchased from Merk Germany. Bulk samples were prepared by solid state reaction at high temperature. $\mathrm{ZnO}$ powder $(99.99 \%)$ was milled thoroughly with $\mathrm{AgNO}_{3}$ powder (99.8\%) in 8 hours. Polyvinyl alcohol was used as cohesion compound. The mixture powder was pressed under pressure of 7 tons $/ \mathrm{cm}^{2}$, then annealed at different temperatures $\left(600^{\circ} \mathrm{C}, 800^{\circ} \mathrm{C}\right.$ and $1200^{\circ} \mathrm{C}$ ) in 4 hours. The products are Ag-doped $\mathrm{ZnO}$ bulk samples with different $\mathrm{Ag}$ concentrations $(0 \%, 1 \%, 2 \%$ and $4 \%)$.

$\mathrm{ZnO}: \mathrm{Ag}$ thin films were deposited by RF sputtering method in Ar atmosphere under operating pressure of $1 \mathrm{~Pa}$ with target made of the as-prepared bulk samples. Sputtering time was 20 minutes while sputtering power was fixed at $175 \mathrm{~W}$. ULVAC's mini Sputter device (Japan) were used to fabricate thin films in this research. The samples were characterized with various techniques including X-ray diffraction (D5005, Druker), Raman scattering spectroscopy LabRam HR800 (Horiba Jobin Yvon), photoluminescence Fluorolog FL3-22 (JobinYvon Spex), Energy dispersive X-Ray spectroscopy, scanning electron microscopy, atomic force microscope AFM XE-100 (Park Systems), absorption spectroscopy Jasco V-750 and Hall measurement HMS-3000 (Ecopia).

\section{Results and discussion}

Fig. 1 presents XRD patterns of Zn:Ag bulk samples (4\% at. of $\mathrm{Ag}$ ) annealed at $600{ }^{\circ} \mathrm{C}, 800{ }^{\circ} \mathrm{C}$ and $1200{ }^{\circ} \mathrm{C}$ in 4 hours. All the samples exhibit polycrystal hexagonal wurtzite C6v structure with 
characteristic difraction peaks corresponding to reflections from (100), (002), (101), (102), (110), (103), (200), (112) and (201) planes. In addition, peaks at $38.01^{\circ}, 44.30^{\circ}$ and $64.34^{\circ}$ in the XRD patterns also suggested the excistence of $\mathrm{Ag}$ in the samples annealed at 600 and $800{ }^{\circ} \mathrm{C}$. The disappeare of these peaks at annealing temperature of $1200{ }^{\circ} \mathrm{C}$ suggested that $\mathrm{Ag}$ had diffused into the lattice of $\mathrm{ZnO}$ and the sample is single phase. The results show that annealing temperature of $1200{ }^{\circ} \mathrm{C}$ is required to obtain pure and single phase sample. Hence, samples doped with 1 , and $2 \%$ of $\mathrm{Ag}$ were also prepared at $1200{ }^{\circ} \mathrm{C}$. The bulk samples were then used as target for fabrication of $\mathrm{Ag}$ doped $\mathrm{ZnO}$ thin films by sputtering method.

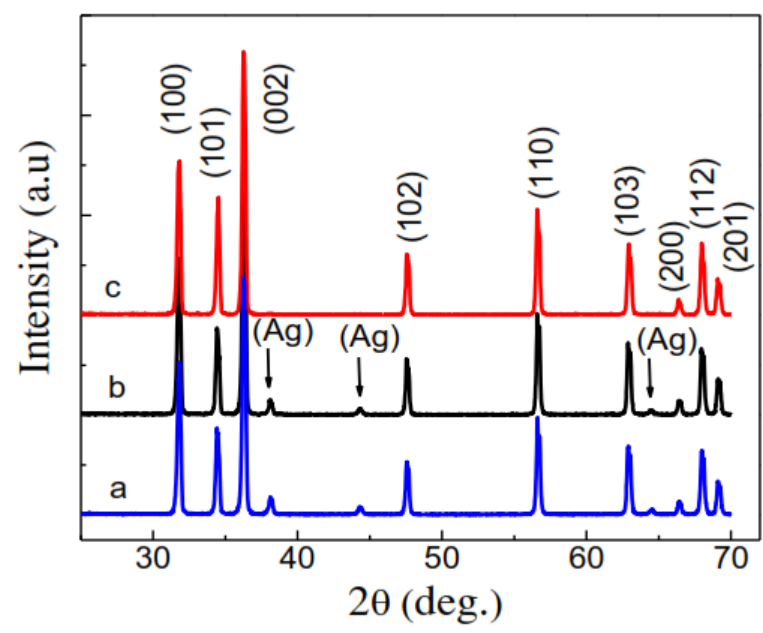

Figure 1. XRD patterns of $\mathrm{ZnO}$ :Ag (4\%) bulk samples annealed at $600^{\circ} \mathrm{C}(\mathrm{a}), 800{ }^{\circ} \mathrm{C}$ (b) and $1200^{\circ} \mathrm{C}$ (c).

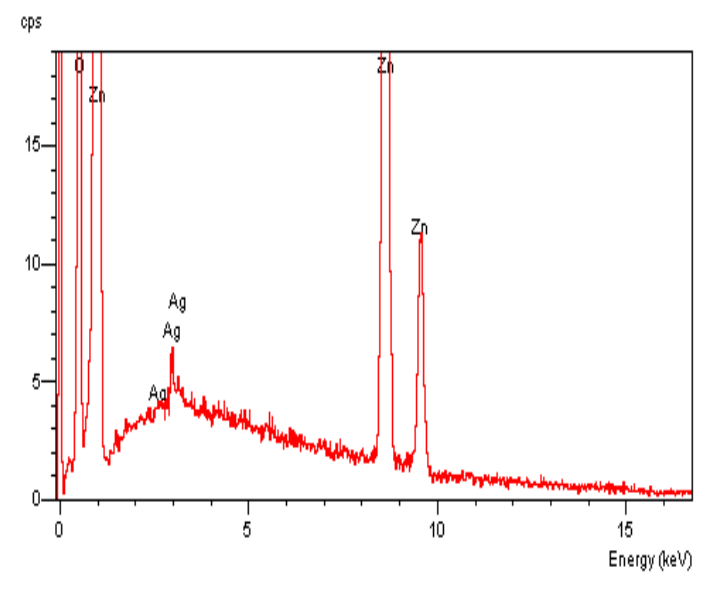

Figure 2. EDS spectrum of thin film $\mathrm{ZnO}$ doped with $4 \% \mathrm{Ag}$, sputtered at $175 \mathrm{~W}$.

Typical EDS spectrum of 4\% Ag-doped thin film (Fig.2) shows that the sample only contains Zn, $\mathrm{O}$ and $\mathrm{Ag}$ and reconfirm the purity of the film. No new peak was observed in Raman spectra (Fig. 3) of samples with various concentration of $\mathrm{Ag}$. The results suggest that $\mathrm{Ag}$ did not change the crystal lattice of $\mathrm{ZnO}$. Two prominent peaks at $\sim 100 \mathrm{~cm}^{-1}\left(\mathrm{E}_{2}^{\text {low }}\right)$ and $438 \mathrm{~cm}^{-1}\left(\mathrm{E}_{2}^{\text {high }}\right)$ correspond to vibration of zinc and oxygen lattice, respectively. $\mathrm{A}_{1}(\mathrm{LO})$ mode, which was absent in Raman spectra of $\mathrm{ZnO}$ thin films, was observed clearly at $570 \mathrm{~cm}^{-1}$ for doped samples. It should be note that the relative intensity of $\mathrm{A}_{1}(\mathrm{LO})$ mode (normalized to $\mathrm{Si}$ peak at $302 \mathrm{~cm}^{-1}$ ) which is commonly considered as a sign of defect or defect complexes of oxygen vacancies, zinc interstitial, increase with doping concentration.

Fig. 4 shows transmission spectra of $\mathrm{Ag}$ doped $\mathrm{ZnO}$ thin films. The undoped sample shows a relatively high transmittance of more than $90 \%$. The doped samples show moderate transmission of above 50\% in the visible region. With increasing concentration of $\mathrm{Ag}$, the transmittance decreases, accompanied with a red shift of the absorption edge. The bandgap energy $\mathrm{E}_{\mathrm{g}}$ of $\mathrm{ZnO}$ and $\mathrm{ZnO}: \mathrm{Ag}$ can be extrapolated by the intersection between the linear part of $(\alpha h v)^{2} \mathrm{vs} . h v$ plot and $\mathrm{x}$ axis. The data is given in Table 1. The bandgap of $\mathrm{ZnO}$ show only slight variation at different doping concentration. 


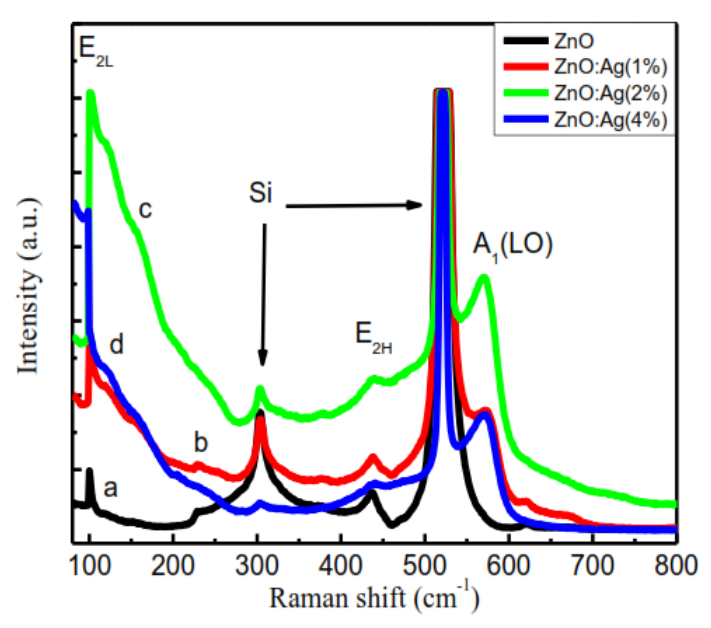

Figure 3. Raman spectra of $\mathrm{ZnO}$ thin film (a) $\mathrm{ZnO}$ doped with $\mathrm{Ag}$ of $1 \%$ (b); $2 \%$ (c) and $4 \%$ (d).

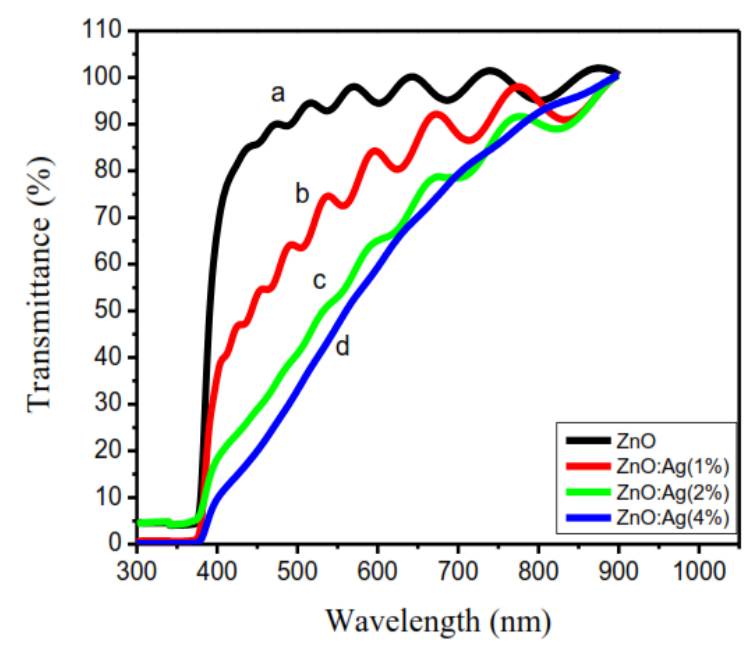

Figure 4. Transmission spectra of $\mathrm{ZnO}$ thin film (a) and $\mathrm{ZnO}$ doped with $\mathrm{Ag}$ of $1 \%$ (b); $2 \%$ (c) and $4 \%(d)$.

Table 1. Band gap of $\mathrm{ZnO}: \mathrm{Ag}$ thin films with different doping concentrations (0\%, $1 \%, 2 \%, 4 \%)$ sputtered at $175 \mathrm{~W}$.

\begin{tabular}{lllll}
\hline Sample & $\mathrm{ZnO}$ & $\mathrm{ZnO}: 1 \% \mathrm{Ag}$ & $\mathrm{ZnO}: 2 \% \mathrm{Ag}$ & $\mathrm{ZnO}: 4 \% \mathrm{Ag}$ \\
\hline $\mathrm{E}_{\mathrm{g}}(\mathrm{eV})$ & 3.23 & 3.23 & 3.12 & 3.20 \\
\hline
\end{tabular}

Hall measurement shows that the grown thin films are n- type, of good conductance with resistivity in the order of $10^{-3} \Omega . \mathrm{cm}$. It should be noted that mobility of $4 \%$ sample is smaller than the sample of lower doping. It can be understood that higher doping likely results in formation of defects due to the difference in radii of $\mathrm{Zn}$ and $\mathrm{Ag}$ ions. These defects will reduce the mobility of carrier in the films. These results agree with the increasing intensity of $A_{1}(L O)$ in Raman spectrum as discussed above. Some Ag atoms might locate at interstitial sites which are also not favorable for creating free carrier. Reduction in carrier concentration and decrement in mobility lead to notable elevation of resistivity of $4 \%$ samples as shown in Table 2 . The lowest resistivity of $1.8 \times 10^{-3} \Omega . \mathrm{cm}$ is achieved for sample doped with $2 \%$ of $\mathrm{Ag}$. The low resistivity of $\mathrm{Ag}$ doped $\mathrm{ZnO}$ thin films in this research is very promising when compared with other reports [9-14] an open the possibility for using as transparent electrode in optoelectronic field.

Table 2. Electrical properties of $\mathrm{ZnO}$ thin films $(1 \%, 2 \%$ and $4 \%$ of $\mathrm{Ag})$ at different sputtering powers.

\begin{tabular}{|c|c|c|c|c|}
\hline $\begin{array}{l}\text { Sputtering } \\
\text { power }\end{array}$ & Thin film & $\begin{array}{l}\text { Carrier concentration } \\
\left(\mathrm{x} 10^{20} \mathrm{~cm}^{-3}\right)\end{array}$ & $\begin{array}{l}\text { Mobility } \\
\left(\mathrm{cm}^{2} / \text { V.s }\right)\end{array}$ & $\begin{array}{l}\text { Restivity } \\
\left(\mathrm{x} 10^{-3} \Omega . \mathrm{cm}\right)\end{array}$ \\
\hline \multirow{3}{*}{$175 \mathrm{~W}$} & $\mathrm{ZnO}: \mathrm{Ag}(1 \%)$ & 1.9 & 18.9 & 3.1 \\
\hline & $\mathrm{ZnO}: \mathrm{Ag}(2 \%)$ & 4.9 & 13.7 & 1.8 \\
\hline & $\mathrm{ZnO}: \mathrm{Ag}(4 \%)$ & 0.2 & 5.5 & 59.7 \\
\hline
\end{tabular}




\section{Conclusion}

$\mathrm{Ag}$ doped $\mathrm{ZnO}$ bulk samples with different $\mathrm{Ag}$ concentrations were prepared by the solid state reaction. XRD patterns show that annealing at $1200{ }^{\circ} \mathrm{C}$ is required for $\mathrm{Ag}$ to diffuse into $\mathrm{ZnO}$ crystal lattice. $\mathrm{Ag}$ doped $\mathrm{ZnO}$ thin film samples were fabricated by RF magnetron sputtering method with target made of the asprepared bulk samples. All thin films are conductive with resistivity in the order of $10^{-3} \Omega . \mathrm{cm}$. Further optimization of synthetic parameter is expected to lower the resistivity and improve the transparency of the films and is currently underway. The good conductivity and transmission of the samples open the possibility to be applied in optoelectronic devices.

\section{Acknowledgement}

This research is funded by VNU University of Science under grant number TN 18.06.

\section{References}

[1] M.L. Lin, J.M. Huang, C.S. Ku, C.M. Lin, H.Y. Lee, J.Y. Juang, High mobility transparent conductive Al-doped $\mathrm{ZnO}$ thin films by atomic layer deposition, J. Alloys Compd. 727 (2017) 565-571. https://doi.org/10.1016/j.jallcom.2017.08.207.

[2] N.V. Tuyen, N.N. Long, T.T.Q. Hoa, N.X. Nghia, D.H. Chi, K. Higashimine, T. Mitani, T.D. Canh, Indiumdoped zinc oxide nanometre thick disks synthesised by a vapour-phase transport process, J. Exp. Nanosci. 4(3) (2009) 243-252. https://doi.org/10.1080/17458080802627482.

[3] C. Moditswe, C.M. Muiva, A. Juma, Highly conductive and transparent Ga-doped ZnO thin films deposited by chemical spray pyrolysis, Optik (Stuttg). 127(20) (2016) 8317-8325. https://doi.org/10.1016/j.ijleo.2016.06.033.

[4] N.V. Tuyen, T.D. Canh, N.N. Long, N.X. Nghia, B.N.Q. Trinh, Z. Shen, Synthesis of undoped and M-doped ZnO (M Co, Mn) nanopowder in water using microwave irradiation, J. Phys. Conf. Ser. 187( 3) (2009) 1-7. 10.1088/1742-6596/187/1/012020

[5] N.T. Huong, N.V. Tuyen, N.H. Hong, Structural properties of P-doped ZnO, Mater. Chem. Phys. 126(1-2) (2011) 54-57. https://doi.org/10.1016/j.matchemphys.2010.12.012.

[6] H.Q. Bian, S.Y. Ma, Z.M. Zhang, J.M. Gao, H. B. Zhu, Microstructure and Raman scattering of Ag-doping ZnO films deposited on buffer layers, J. Cryst. Growth, 394 (2014) 132-136. https://doi.org/10.1016/j.jcrysgro.2014.02.036

[7] R. Sánchez Zeferino, M. Barboza Flores, and U. Pal, Photoluminescence and raman scattering in ag-doped zno nanoparticles, J. Appl. Phys. 109(1) (2011) 014308(1)-014308(6). https://doi.org/10.1063/1.3530631.

[8] L.N.Wang, L.Z.Hu, H.Q.Zhang, Y.Qiu, Y.Lang, G.Q.Liu, J.Y.Ji, J.X.Ma, Z.W.Zhao, Studying the Raman spectra of Ag doped ZnO films grown by PLD, Mater. Sci. Semicond. Process. 14(3-4) (2011) 274-277. https://doi.org/10.1016/j.mssp.2011.05.004.

[9] M.A. Myers, V. Khranovskyy, J. Jian, J.H. Lee, H. Wang, H. Wang, Photoluminescence study of p-type vs. ntype Ag-doped ZnO films, J. Appl. Phys. 118 (6) ( 2015) 065702(1)-065702(7). https://doi.org/10.1063/1.4928183.

[10] R.K. Gupta, K. Ghosh, P.K. Kahol, Effect of substrate temperature on structural and optoelectrical properties of silver doped zinc oxide thin films, Phys. E Low-Dimensional Syst. Nanostructures 42(7) (2010) 2000-2004. https://doi.org/10.1016/j.physe.2010.03.010.

[11] I.S. Kim, E.K. Jeong, D.Y. Kim, M. Kumar, S.Y. Choi, Investigation of p-type behavior in Ag-doped ZnO thin films by E-beam evaporation, Appl. Surf. Sci. 255(7) (2009) 4011-4014.

https://doi.org/10.1016/j.apsusc.2008.10.117 
[12] R. Deng et al., Influence of oxygen/argon ratio on structural, electrical and optical properties of Ag-doped $\mathrm{ZnO}$ thin films, J. Cryst. Growth 312 (11) (2010) 1813-1816. Doi:10.1016/j.jcrysgro.2010.02.042

[13] F. Lekoui, M. Ouchabane, H. Akkari, S. Hassani, D. Dergham, Effect of annealing temperature on the properties of $\mathrm{Ag}$ doped $\mathrm{ZnO}$ thin films, Mater. Res. Express, 5(10) ( 2018) 1-8. Doi: https://doi.org/10.1088/20531591/aadafa

[14] A.N. Afaah, N.A.M. Asib, A. Aadila, R. Mohamed, M. Rusop, Z. Khusaimi, Electrically conductive nanostructured silver doped zinc oxide (Ag:ZnO) prepared by solution-immersion technique, AIP Conf. Proc., vol. 1733 ( 2016) 020055(1)- 020055(6). Doi: https://doi.org/10.1063/1.4948873. 